\title{
An Extension Fuzzy Analysis Model of the Performance of Education Management for Higher Education
}

\author{
Chen Cuilan \\ Mechanic Engineering School of Chongqing Technology and Business University, \\ Chongqing, China. \\ 15922522442@163.com
}

\begin{abstract}
Many factors hold key to educational management for higher learning. An analysis of the performance of educational management is crucial to help higher education institutions enhance teaching ability and quality. This paper proposes an extension fuzzy analysis model to evaluate the performance of education management for higher education. First, it constructs a comprehensive index system for the performance of education management. And standardize quantitative and qualitative indicators in the index system. It then constructs an extension distance model of different performance evaluation indicators about the classical domain and the section domain. And a performance evaluation model based on fuzzy and extension correlation is established. The performance of education management is measured by correlation. Finally, a case study has proved that the model is practical and available.
\end{abstract}

Keywords: higher education; educational management; performance analysis; extensive theory; fuzzy theory

\section{Introduction}

With science and technology change with every passing day, the educational goal and management mode for higher education are taking a new shape. It owes to educators to coordinate higher education and social development [1-4]. Evaluating the performance of educational management has received widely attentions in that it is an effective way to measure the teaching ability and quality of higher education. Research has been conducted with fruitful results [5-9]. However, there is still much room to improve. Weaknesses of current research include: (1) the selection of indicators is not objective enough, so that the study cannot reach a generalized conclusion; (2) qualitative analysis weights more than quantitative analysis and no quantitative model is applied. So the analysis is not reliable enough. (3) fuzzy information is not deal with in a proper way. Though some studies abide by fuzzy theory, much subjectivity is added to fuzzy analysis, influencing the effectiveness of the result.

Therefore, based on previous research, this paper follows fuzzy theory [10-12] and extension theory [13-15] and proposes a fuzzy and extension correlation model of the performance of educational management for higher education. It aims at stressing the importance of educational management and improving the ability and quality of educational management of higher education.

\section{Index System for the Performance of Education}

This paper investigates current educational management of higher education. It constructs the index system for the performance of education management for higher education from three perspectives, namely, school management, teacher management and 
student management. The index system is established based on previous research and analysis and under the guiding principle of scientific, objective, systematic, representable, measurable, and hierarchical.

School management: it mainly studies how administrators play a role in the performance of educational management. Administrators are the planner and server of educational management. Their management ability, the efficiency, the organizing mechanism and software and hard wares are key factors for the analysis.

Teacher management: it mainly studies teachers' ability of teaching and research in the performance of educational management. Teachers are executers of educational management. Their overall quality and teaching ability are important links of the analysis.

Student management: it mainly studies students' overall quality and ability to measure the effect of educational management. It directly reflects the teaching ability and quality of higher education.

The index system for the performance of education management for higher education is shown in Table 1.

\section{Table1. Index System for the Performance of Education Management for Higher Education}

\begin{tabular}{|c|c|c|c|}
\hline $\begin{array}{l}\text { Class of } \\
\text { indicators }\end{array}$ & $\begin{array}{l}\text { First class } \\
\text { indicator }\end{array}$ & Second class indicator & $\begin{array}{l}\text { Type of } \\
\text { indicator }\end{array}$ \\
\hline \multirow{16}{*}{$\begin{array}{c}\text { Index } \\
\text { system for } \\
\text { the } \\
\text { performance } \\
\text { of education } \\
\text { management } \\
\text { for higher } \\
\text { education } \\
U\end{array}$} & \multirow{8}{*}{$\begin{array}{c}\text { School } \\
\text { management } U_{1}\end{array}$} & $\begin{array}{l}\text { Completeness of organizing } \\
\text { structure } u_{11}\end{array}$ & Qualitative \\
\hline & & $\begin{array}{l}\text { Rationality of the incentive } \\
\text { mechanism } u_{12}\end{array}$ & Qualitative \\
\hline & & $\begin{array}{l}\text { Efficiency of the service } \\
\text { department } u_{13}\end{array}$ & Quantitative \\
\hline & & Rationality of course setting $u_{14}$ & Qualitative \\
\hline & & $\begin{array}{l}\text { Satisfaction to the } \\
\text { administration } u_{15}\end{array}$ & Quantitative \\
\hline & & School investment $u_{16}$ & Qualitative \\
\hline & & $\begin{array}{l}\text { Discipline platform building } \\
\text { ability } u_{17}\end{array}$ & Qualitative \\
\hline & & Decision making ability $u_{18}$ & Qualitative \\
\hline & \multirow{8}{*}{$\begin{array}{c}\text { Teacher } \\
\text { management } U_{2}\end{array}$} & Teaching quality $u_{21}$ & Qualitative \\
\hline & & Number of course reform $u_{22}$ & Quantitative \\
\hline & & Course planning ability $u_{23}$ & Qualitative \\
\hline & & $\begin{array}{l}\text { Number of core papers and } \\
\text { textbooks } u_{24}\end{array}$ & Quantitativ \\
\hline & & $\begin{array}{c}\text { Number of research papers, } \\
\text { journals and academic works } \\
u_{25}\end{array}$ & Quantitativ \\
\hline & & Number of research project $u_{26}$ & e $\quad$ Quantitativ \\
\hline & & $\begin{array}{l}\text { Number of teaching } \\
\text { achievement prize } u_{27}\end{array}$ & Quantitativ \\
\hline & & Number of research & Quantitativ \\
\hline
\end{tabular}




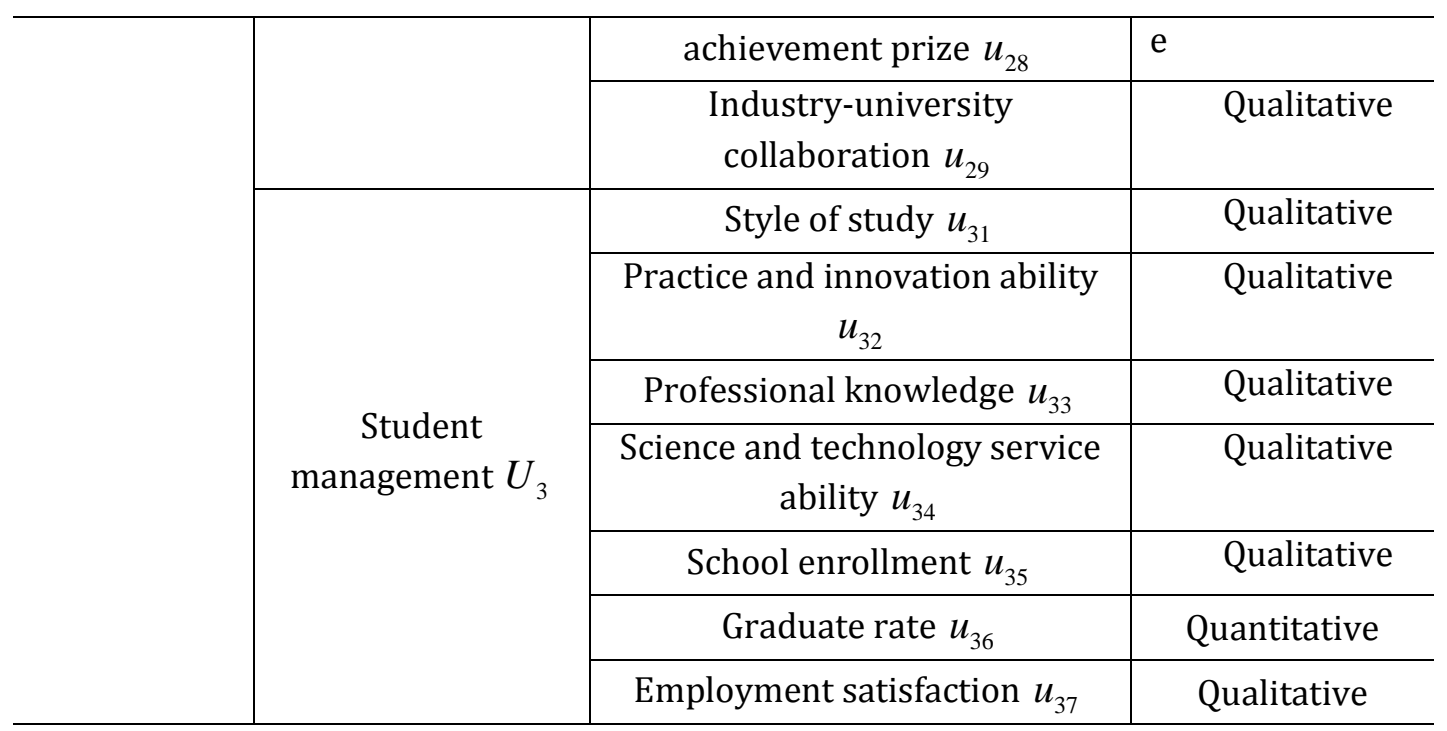

\section{Extension Fuzzy Analysis Model of the Performance of Educational Management for Higher Learning}

From the abovementioned index system, the performance analysis of educational management is a multi-layer one with various factors. Some factors and fuzzy and uncertain. Thus, we need to analyze the hidden information of fuzzy indicators according to fuzzy theory and extension theory.

\subsection{Constructing Factor Set for the Performance Analysis of Educational Management}

The factor set for the performance analysis of educational management has two layers of indicators. The first class of factor set is expressed by $U$ :

$U=\left\{U_{1}, U_{2}, U_{3}\right\}$

The second class of factor set is expressed by $U_{i}$

$U_{1}=\left\{u_{11}, u_{12}, u_{13}, u_{14}, u_{15}, u_{16}, u_{17}, u_{18}\right\}$

$U_{2}=\left\{u_{21}, u_{22}, u_{23}, u_{24}, u_{25}, u_{26}, u_{27}, u_{28}, u_{29}\right\}$

$U_{3}=\left\{u_{31}, u_{32}, u_{33}, u_{34}, u_{35}, u_{36}, u_{37}\right\}$

\subsection{Standardization of Indicators}

As there are two types of indicators, namely, qualitative and quantitative indicator, we need to standardize them.

1. Standardize qualitative indicator

If the value of quantity of a qualitative indicator $u_{i}$ is expressed by membership degree $f^{\prime}\left(u_{i}\right)$, when it is a cost indicator, its standardized value of quantity $v_{i}$ of $u_{i}$ is: $v\left(u_{i}\right)=1-f\left(u_{i}\right)$

When $u_{i}$ is a benefit indicator, its standardized value of quantity $v_{i}$ of $u_{i}$ is: $v\left(u_{i}\right)=f\left(u_{i}\right)$

If the qualitative indicator $u_{i}$ is described by qualitative fuzzy language, then use the scale of $0-1$ to get the value of quantity. Its standardized value of quantity ${ }_{i}$ of ${ }^{u_{i}}$ is: 
$v_{i}=\left[v_{i}^{\min }, v_{i}^{\max }\right], 0 \leq v_{i}^{\min } \leq v_{i}^{\max } \leq 1$

2. Standardize qualitative indicator
$p_{i}^{\text {milnpposerax }}-p_{i}$ the original value of quantity of indicator $u_{i}$ is $p\left(u_{i}\right)=\left[p_{i}^{\min }, p_{i}^{\max }\right]$, and
$u_{i}$, $p_{i}^{m}=p_{i}$, when $u_{i}$ is a benefit indicator, the standardized value of quantity $v_{i}$ of $u_{i}$ is:

$v_{i}=\left[v_{i}^{\min }, v_{i}^{\max }\right]=\left[\frac{p_{i}^{\min }-\inf \left(p_{i}^{\min }\right)}{\sup \left(p_{i}^{\max }\right)-\inf \left(p_{i}^{\min }\right)}, \frac{p_{i}^{\max }-\inf \left(p_{i}^{\min }\right)}{\sup \left(p_{i}^{\max }\right)-\inf \left(p_{i}^{\min }\right)}\right]$

In particular, when $p_{i}^{\min }=p_{i}^{\max }$, the standardized value of quantity $v_{i}$ of $u_{i}$ is:

$v_{i}=\frac{p\left(u_{i}\right)-\inf \left(p\left(u_{i}\right)\right)}{\sup \left(p\left(u_{i}\right)\right)-\inf \left(p\left(u_{i}\right)\right)}$

When $u_{i}$ is a cost indicator, the standardized value of quantity $v_{i}$ of $u_{i}$ is:

$v_{i}=\left[v_{i}^{\min }, v_{i}^{\max }\right]=\left[\frac{\sup \left(p_{i}^{\max }\right)-p_{i}^{\min }}{\sup \left(p_{i}^{\max }\right)-\inf \left(p_{i}^{\min }\right)}, \frac{\sup \left(p_{i}^{\max }\right)-p_{i}^{\max }}{\sup \left(p_{i}^{\max }\right)-\inf \left(p_{i}^{\min }\right)}\right]$

In particular, when $p_{i}^{\min }=p_{i}^{\max }$, the standardized value of quantity $v_{i}$ of $u_{i}$ is:

$v_{i}=\frac{\sup \left(p\left(u_{i}\right)\right)-p\left(u_{i}\right)}{\sup \left(p\left(u_{i}\right)\right)-i n f\left(p\left(u_{i}\right)\right)}$

\subsection{Obtain the Weight Set for Indicator Analysis}

The influence of second class indicators on first class indicators does not vary too much from each other. And the first class indicators pose influence on the performance of educational management from three perspectives. In this paper, we allocate weight to second class indicators based on AHP.

According to the grade of first class indicators given by experts, we can get the judgment matrix $\boldsymbol{G}$ for first class indicators:

$\boldsymbol{G}=\left[\begin{array}{cccc}g_{11} & g_{12} & \cdots & g_{1 n} \\ g_{21} & g_{22} & \cdots & g_{2 n} \\ \vdots & \vdots & \cdots & \vdots \\ g_{n 1} & g_{n 2} & \cdots & g_{n n}\end{array}\right]_{n \times n}$

With the maximum eigenvalue $\max \left(\lambda_{(\boldsymbol{G})}\right)$ of e judgment matrix $\boldsymbol{G}$, we can construct the consistent indicators:

$\left\{\begin{array}{l}C I=\left(\max \left(\lambda_{(G)}\right)-n\right) / n-1 \\ C R=C I / R I\end{array}\right.$

If a first class indicator meets the requirement of a consistent indicator, the weight of this indicator is:

$w_{i}=\left(\sum_{j=1}^{n} g_{i j}\right) /\left(\sum_{i=1}^{n} \sum_{k=1}^{n} g_{i k}\right)$

The sequence $W$ of the first class indicator for performance evaluation is:

$W=\left\{w_{1}, w_{2}, w_{3}\right\}, 0 \leq w_{1}, w_{2}, w_{3} \leq 1, w_{1}+w_{2}+w_{3}=1$ 


\subsection{Construct Evaluation Set and Classical Domain}

The evaluation set for the performance analysis of educational management is for the purpose of evaluating the grade of educational management. After consulting with experts, this paper select excellent, good, mediocre and poor to form an evaluation set $\Omega$. $\Omega=\left\{\Omega_{E L}, \Omega_{G L}, \Omega_{M L}, \Omega_{P L}\right\}$

Thus, we can construct element for classical domain $R\left(\Omega_{x}\right)$ and element for section domain $R\left(\Omega_{o}\right)$ under different grades:

$$
\begin{aligned}
R\left(\Omega_{x}\right) & =\left[\begin{array}{ccc}
N_{x} & c_{x 1} & v_{x 1} \\
& c_{x 2} & v_{x 2} \\
& \vdots & \vdots \\
& c_{x n} & v_{x n}
\end{array}\right] \\
R\left(\Omega_{o}\right) & =\left[\begin{array}{ccc}
N_{0} & c_{1} & {\left[\min \left(v_{x 1}\right), \max \left(v_{x 1}\right)\right]} \\
& c_{2} & {\left[\min \left(v_{x 2}\right), \max \left(v_{x 2}\right)\right]} \\
& \vdots & \vdots \\
& c_{n} & {\left[\min \left(v_{x n}\right), \max \left(v_{x n}\right)\right]}
\end{array}\right]
\end{aligned}
$$

Where ${ }^{x}$ refers to $E L, G L, M L, P L$.

\subsection{Extension Fuzzy Distance of the Performance Analysis}

If the value of quantity for indicator $u_{i}$ after standardization is $v_{i}$, the extension distance $\rho_{x i}^{R}$ between classical domain $R\left(\Omega_{x}\right)$ and indicator $u_{i}$ is:

$\rho_{x i}^{R}=\left|v_{i}-\frac{v_{x i}^{\min }+v_{x i}^{\max }}{2}\right|+\frac{v_{x i}^{\min }-v_{x i}^{\max }}{2}$

Correspondingly, the extension distance $\rho_{o i}^{R}$ between section domain $R\left(\Omega_{o}\right)$ (19) indicator $u_{i}$ is:

$\rho_{o i}^{R}=\left|v_{i}-\frac{v_{o i}^{\min }+v_{o i}^{\max }}{2}\right|+\frac{v_{o i}^{\min }-v_{o i}^{\max }}{2}$

If the value of quantity for indicator $u_{i}$ after tagdardization is $v_{i}=\left[v_{i}^{\min }, v_{i}^{\max }\right]_{\text {, the }}^{(20)}$ extension distance $\rho_{x i}$ between classical domain $R\left(\Omega_{x}\right)$ and indicator $u_{i}$ is:

$\rho_{x i}^{R}=\frac{\left|v_{i}^{\text {min }}-\frac{v_{x i}^{\text {min }}+v_{x i}^{\text {max }}}{2}\right|+\left|v_{i}^{\max }-\frac{v_{x i}^{\text {min }}+v_{x i}^{\text {max }}}{2}\right|+\left(v_{x i}^{\text {min }}-v_{x i}^{\text {max }}\right)}{2}$

Correspondingly, the extension distance $\rho_{o i}^{R}$ between section domain $R\left(\Omega_{o}\right)^{(21)}$ and indicator $u_{i}$ is:

$\rho_{o i}^{R}=\frac{\left|v_{i}^{\min }-\frac{v_{o i}^{\min }+v_{o i}^{\max }}{2}\right|+\left|v_{i}^{\max }-\frac{v_{o i}^{\min }+v_{o i}^{\max }}{2}\right|+\left(v_{o i}^{\min }-v_{o i}^{\max }\right)}{2}$

\subsection{Extension Fuzzy Correlation Degree for the Performance Analysis}


With the extension distance obtained, we can get the correlation extension coefficient $K_{x i}^{R}$ between classical domain $R\left(\Omega_{x}\right)$ and indicator ${ }{ }_{i}$ :

$K_{x i}^{R}= \begin{cases}-\rho_{x i}^{R} /\left|v_{x i}\right| & v_{i} \vee\left(v_{i}^{\min }, v_{i}^{\max }\right) \in\left(v_{o i}^{\min }, v_{o i}^{\max }\right) \\ \rho_{x i}^{R} /\left(\rho_{o i}^{R}-\rho_{x i}^{R}\right) & v_{i} \vee\left(v_{i}^{\min }, v_{i}^{\max }\right) \notin\left(v_{o i}^{\min }, v_{o i}^{\max }\right)\end{cases}$

If there are $N$ second class indicators, the extension fuzzy correlation $\tau_{x i}^{I I}$ of second class indicators is:

$\tau_{i}^{I I}=\frac{1}{N} \sum_{i}^{N} K_{x i}^{R}$

If the weight of first class indicator is considered, the weighed extension fuzzy correlation $\tau_{x i}^{I}$ of first class indicators is:

$\tau_{x i}^{I}=\sum_{i=1}^{M}\left(w_{i} * \tau_{x i}^{I I}\right)$

According to the optimization principle, if there is:

$\tau_{0}=\max _{1 \leq x \leq T}\left(\tau_{x i}^{I}\right)=\varphi_{t}, 1 \leq t \leq T$

Where $\mathrm{T}$ refers to the grade of current performance analysis, then the educational management of the higher education being analyzed belongs to $t$-th performance level.

\section{Case Study}

This paper takes the educational management of a key university at province-level as the example to check the efficacy of the algorithm. After surveys, indicators are standardizing (See Table 2). AHP is applied to allocate weight for first class indicators.

Table 2. Performance Analysis of Educational Management for Higher Education

\begin{tabular}{|c|c|c|c|c|c|c|c|c|}
\hline \multirow{2}{*}{$\begin{array}{l}\text { First } \\
\text { class } \\
\text { indicator }\end{array}$} & \multirow[b]{2}{*}{$\mathrm{W}$} & \multirow{2}{*}{$\begin{array}{l}\text { Second } \\
\text { class } \\
\text { indicator }\end{array}$} & \multirow{2}{*}{$\begin{array}{l}\text { Original } \\
\text { value of } \\
\text { quantity }\end{array}$} & \multirow{2}{*}{$\begin{array}{l}\text { Standardized } \\
\text { value of } \\
\text { quantity }\end{array}$} & \multicolumn{4}{|c|}{ Classical domain } \\
\hline & & & & & $R\left(\Omega_{E L}\right)$ & $R\left(\Omega_{G L}\right)$ & $R\left(\Omega_{M L}\right)$ & $R\left(\Omega_{P L}\right)$ \\
\hline
\end{tabular}

According to the extension distance and extension correlation function model, it can acquire extension distance and extension correlation function between classical domains and different indicators for this university, as is shown in Table 3.

Table 3. Extension Distance and Extension Correlation Function

\begin{tabular}{l|l|l|l|l|l|l|l|l}
\hline $\begin{array}{l}\text { Second } \\
\text { class } \\
\text { indicator }\end{array}$ & \multicolumn{4}{|l|}{ Extension distance } & \multicolumn{4}{l}{ Correlation function } \\
\cline { 2 - 8 } & $R\left(\Omega_{E L}\right)$ & $R\left(\Omega_{G L}\right)$ & $R\left(\Omega_{M L}\right)$ & $R\left(\Omega_{P L}\right)$ & $R\left(\Omega_{E L}\right)$ & $R\left(\Omega_{G L}\right)$ & $R\left(\Omega_{M L}\right)$ & $R\left(\Omega_{P L}\right)$ \\
\hline
\end{tabular}

With the weight of the first class indicators considered, and using the comprehensive extension fuzzy correlation model, we can get the comprehensive extension fuzzy correlation sequence $\tau=(-0.162,-0.038,-0.182,-0.491)$ between different grades of classical domains for this university. Thus, we can judge that the educational management of this university can be marked as "good".

\section{Conclusion}


Aimed at solving current problems in performance evaluation of educational management of higher education, this paper proposes a new index system for the performance analysis. It constructs the classical domain and the section domain for evaluating indicators after standardizing quantitative and qualitative indicator. It then computes the extension distance and extension correlation coefficient between classical domain and section domain to further establish the extension fuzzy correlation model, so as to evaluate the performance level of educational management. This model is simple, operable and easy to achieve on the computer. Case study has proved its

\section{References}

[1] M. Guangshui, "The Application of EAP and Educational Management of Higher Education", Seeker, vol. 11, (2011), pp. 182-183.

[2] Z. Xianglin, "The Reform of Educational Management in the Age of Big Data", Journal of The Chinese Society of Education, vol. 10, (2014), pp. 25-30.

[3] W. Yan, "Analysis by DEA on the Efffectiveness of High Education Management", Theory Monthly, vol. 11, (2010).

[4] L. Jian, Z. Xinping, "Research Methodologies of Educational Management: Meaning, Feature and Transformation", Educational Research and Experiment, vol. 3, (2011), pp. 43-46.

[5] W. Hanmei, "Quantitative Analysis in the Use of Educational Administration", Heilongjiang Researches on Higher Education, vol. 1, (2010).

[6] S. Baiqing, "Method for evaluating the performance of scientific research management in universities", Journal of Harbin Engineering University, (2010), vol. 31, no. 6, (2010).

[7] X. Jinfen, Z. Shi, "The application of input-output model in performance evaluation of university research and development", Science and Technolgy Managemenr Research, vol. 2, (2010).

[8] X. Dong, "The Grey Principle of The Assessment of Education Management", Liaoning Education Rsearch, vol. 2, (2002).

[9] T. Qing, G. Fuyan, "For Improving Educational Management of Higher Education", Education and Vocation, vol. 20, (2014), pp. 24-25.

[10] W. Yawei, Z. Xiangwei, W. Jianping, "Evaluation of Classroom Teaching Quality in Universities based on the Improved Fuzzy Comprehensive Evaluation Model", Mathematics in Practice and Theory, vol. 42, no. 5, (2012), pp. 10-16.

[11] L. Ming, "Study on Human Resources Competitiveness of Enterprise Based on Interval number Fuzzy Comprehensive Evaluation", Enterprise Economy, vol. 3, (2013), pp. 92 - 95.

[12] Y. Fanglan, Y. Minglang, L. Weidong, "Evaluation of automobile form design based on fuzzy TOPSIS", Computer Integrated Manufacturing Systems, vol. 20, no. 2, (2014), pp. 276-283.

[13] C. Wen, Y. Chunayn, "Basic Theory and Methodology of Extenics", Chinese Science Bulletin, vol. 58, no. 13, (2013), pp.1190-1199

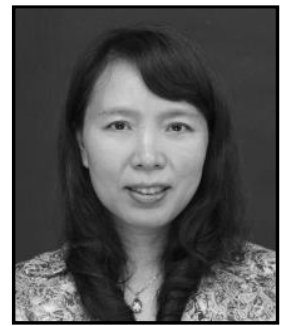

Chen Cuilan Chen Cuilan (1969-10), female, Da Zu, Chongqing, associate professor of Chongqing Technology and Business University, LLM, research interests: Ideological \& Political Education, Party Building. 
International Journal of $u-$ and $e-$ Service, Science and Technology Vol.8, No.3 (2015) 